\title{
UNDO, REDO, DELETE: VISIONES DEL HOGAR Y SUS IMPLICACIONES EN LA LITERATURA HISPANOAMERICANA CONTEMPORÁNEA
}

\author{
DÓRA BAKUCZ
}

Universidad Católica Pázmány Péter

\begin{abstract}
Resumen: En el artículo se analizan tres cuentos de tres autoras hispanoamericanas (dos argentinas, Ana María Shua y Samantha Schweblin, así como una chilena, Andrea Jeftanovic), que de alguna manera u otra dan una visión de las condiciones del cambio del hogar y sus implicaciones, como la familia y las relaciones familiares, en las sociedades contemporáneas. En el plano teórico partimos de las ideas de Zygmunt Bauman sobre la "modernidad líquida" y "el amor líquido" que caracteriza las sociedades de hoy, y utilizamos la metáfora de los comandos de los procesadores de texto: undo, redo, delete.
\end{abstract}

Palabras clave: hogar, relaciones humanas, amor líquido, literatura contemporánea, cuento hispanoamericano

\begin{abstract}
In the article three short stories will be analized from three Spanish-American authors (two Argentines, Ana María Shua and Samantha Schweblin, and a Chilean, Andrea Jeftanovic), who in some way give a vision of the conditions how home and its implications like family and human relationships change in contemporary societies. On the theoretical level, we start from ideas of Zygmunt Bauman about "liquid modernity" and "liquid love" that depict today's societies' nature, and for the interpretation we use the metaphor of the commands in modern editing software functions: undo, redo, delete.
\end{abstract}

Key words: home, human relationships, liquid love, contemporary literatura, Spanish-American short story

\section{Hogar y amor líquido}

El concepto del hogar no solo designa un espacio, sino también las relaciones humanas y las unidades sociales que lo convierten en algo relacionado con cierta seguridad, unión y pertenencia. Sin embargo, en las sociedades de hoy, descritas como de "individuos líquidos modernos" (Bauman, 2017), o de "comunidades de una sola persona" (Csányi, 2015), o de los "hombres desconectados" (Zimbardo, 2015) o de un "narcisismo patológico" (Slavoj Žižek, 2014) el hogar y lo que implica, como la familia o los nexos humanos, cambian, muchas veces incluso de forma radical. El propósito de este trabajo es estudiar algunas estampas literarias 
de dichos cambios en tres cuentos de autoras hispanoamericanas contemporáneas (las tres mujeres, dos argentinas y una chilena), partiendo del concepto de "amor líquido" de Zygmunt Bauman.

Los textos que analizaremos son "Conservas" de Samantha Schweblin (Argentina), "El mismo río" de Ana María Shua (Argentina) y "Árbol genealógico" de la chilena Andrea Jeftanovic.

Muchos psicólogos y sociólogos resaltan la relación entre dichos cambios y el uso cotidiano de la tecnología, internet, los móviles, y todas sus consecuencias: las relaciones virtuales, la inmediatez, la falta de paciencia, la falta de tolerancia, el miedo a la responsabilidad y al arraigo, o la necesidad de una cantidad exagerada de impulsos.

Bauman, en el prólogo de su libro que lleva justamente el título de Amor líquido, encontramos la siguiente cita:

Un hombre de Bath, de 28 años, entrevistado en relación con la creciente popularidad de las citas por Internet en desmedro de los bares de solas y solos, y las columnas de corazones solitarios, señaló una ventaja decisiva de la relación electrónica: uno siempre puede oprimir la tecla delete (Bauman, 2006:13).

Sin embargo, después, analizando las relaciones entre las personas de hoy día, o, con palabras del mismo Bauman, las del "habitante de nuestra moderna sociedad líquida", o sea, los "amores líquidos", habla más bien de un fenómeno bastante contradictorio que se caracteriza por una búsqueda y un rechazo al mismo tiempo, que, hablando de funciones de los procesadores de texto, quizás corresponda más a lo que nos ofrecen como posibilidad las teclas (o las combinaciones de teclas) de undo (deshacer) y redo (rehacer o volver a hacer), de lo que en una página web colaborativa de definiciones encontramos la siguiente explicación:

Este comando podría llamarse salva-vidas, ya que lo que hace es rehacer el último cambio que has realizado (tu último error), dejando en perfecto estado tu creación como si nada hubiera pasado. Lo contrario es REDO, el cual significa volver a aplicar ese cambio que acabas de rehacer con UNDO (significado-diccionario). 
A nuestro modo de ver, algo parecido ocurre en los dos primeros textos, en los de las autoras argentinas: los protagonistas se encuentran en situaciones que en un momento dado no son capaces de continuar, y en sus vidas, en algún sentido, hacen clic en la tecla undo para que más tarde, en un futuro -indeterminado en el primer caso y determinado en el segundo- puedan pasar a aplicar la otra tecla, la de redo. En caso del tercer texto podremos observar una versión literaria de la aplicación del comando delete, en un contexto humano. Pero todos estos procesos que parecen (y son) tan simples en el ordenador, en la vida de los protagonistas se vuelve en una cuestión mucho más complicada.

\section{Un undo (y futuro redo) personal - "Conservas" de Samantha Schweblin}

En "Conservas" de Samantha Schweblin la protagonista es una mujer joven embarazada que se arrepiente de tener un hijo, mejor dicho, una hija, que incluso tiene ya nombre: Teresita. Pero no se trata de un arrepentimiento para siempre, lo que quiere no es abortar, no es no tener la hija, sino tenerla en otro momento, más tarde, en un futuro indefinido. Es decir, lo que desea, es to undo, deshacer el embarazo, pero de manera que quede ahí la posibilidad de to redo, volver a hacerlo en el momento que a ella le parezca oportuno.

En la práctica ficticia de la narración esto ocurre de la manera siguiente: buscando una solución que permita aplicar tanto undo como redo (en el futuro), resulta que un tal doctor Weisman sabe cuál es el método que incluye "cambios en la alimentación, en el sueño, ejercicios de respiración, medicamentos" (Schweblin, 2017). La narración es en primera persona y en presente, construida de manera que el lector pueda seguir paso a paso, y de una forma muy natural (como si nos lo estuviera explicando una amiga, en plan confidencial) las preocupaciones de la protagonista relacionadas con el embarazo: la deformación del cuerpo, el cambio de la relación con su pareja, las posibilidades y placeres a las que se ve obligada a renunciar, entre otras. En el discurso de la narración la incertidumbre empieza de una manera muy suave, con unos "no sé-s" al recibir un regalo de su madre para la futura nieta:

-Ay, no sé... - digo yo, y no sé si me refiero al regalo o a Teresita.

La verdad es que no sé -le digo más tarde a mi suegra cuando cae con un juego de sabanitas de colores-, no sé - digo ya sin saber qué decir, y abrazo las sábanas y me largo a llorar (Schweblin, 2017). 
Undo, redo, delete: visiones del hogar y sus implicaciones

en la literatura hispanoamericana contemporánea

Lo emocional pronto se manifiesta también en forma psicosomática, y a continuación, cuando la protagonista reflexiona sobre los hechos, pasa a un nivel más racional:

Tengo insomnio. Paso las noches despierta, en la cama. Miro el techo con las manos sobre la pequeña Teresita. No puedo pensar en nada más. No puedo entender cómo en un mundo en el que ocurren cosas que todavía me parecen maravillosas, como alquilar un coche en un país y devolverlo en otro, descongelar del freezer un pescado fresco que murió hace treinta días, o pagar las cuentas sin moverse de casa, no pueda solucionarse un asunto tan trivial como un pequeño cambio en la organización de los hechos. Es que simplemente no me resigno (Schweblin, 2017).

Con la ayuda del doctor Weisman, y como resultado de un penosamente largo proceso, la narradora-protagonista logra revertir el embarazo y al final de la historia escupe "algo pequeño, del tamaño de una almendra" (Schweblin, 2017) que podrá conservar en un vaso y así colocarlo en un envase especial para poder tener la hija en otro momento (to redo). En las críticas relacionadas al texto encontramos sobre todo lecturas que parten del tema de la maternidad, o la manifestación de la autonomía corporal de la mujer. ${ }^{1}$

Sin embargo, lo que nosotros proponemos en este trabajo, es dar un paso hacia atrás y alejándonos un poco tanto de las teorías literarias como de la problemática de la situación de la mujer, observar la actitud de los protagonistas (ya que la decisión es de los dos, no hay ningún conflicto, novio y novia, hombre y mujer, son representantes iguales del mismo hogar -para usar la palabra y la imagen que da título a esta publicación), partiendo de las ideas de Bauman que intentábamos introducir con los conceptos de undo y redo.

El sociólogo-filósofo polaco, en su libro ya mencionado, Amor líquido, compara el héroe de Musil, Der Mann obne Eigenschaften (el hombre sin atributos) con el de su texto que sería "Der Mann ohne Verwandtschaften, el hombre sin vínculos, y particularmente sin vínculos tan fijos y establecidos como solían ser las relacio-

${ }^{1}$ Valdría la pena también analizar el cuento desde el punto de vista de cómo se construye la narración, cuáles son los puntos en los que el lector cae en las trampas de unos esquemas mentales influidos por los discursos políticos, sociales, teóricos dominantes, y también desde el punto de vista de lo fantástico, categoría en la cual se suele colocar la escritora, pero nuestro propósito esta vez es otro. 
nes de parentesco en la época de Ulrich.” (Bauman, 2006:7) Y desde la época de Ulrich hasta hoy día ni siquiera han pasado cien años. Bauman ha escrito mucho sobre las consecuencias de lo que él llama "modernidad líquida" (o modernidad tardía que es lo que en su lectura caracteriza las sociedades de la era de la globalización), y describe las relaciones humanas como "una bendición a medias", ya que "en nuestro mundo de rampante individualización, las relaciones $[\ldots]$ oscilan entre un dulce sueño y una pesadilla, y no hay manera de decir en qué momento uno se convierte en la otra" (2006:8). Dice que nuestros contemporáneos están

\begin{abstract}
desesperados por "relacionarse". Sin embargo, desconfían todo el tiempo del "estar relacionados", y particularmente de estar relacionados "para siempre", por no hablar de "eternamente", porque temen que ese estado pueda convertirse en una carga y ocasionar tensiones que no se sienten capaces ni deseosos de soportar, y que pueden limitar severamente la libertad que necesitan (2006:8).
\end{abstract}

Más tarde, resume el fenómeno como algo parecido a "cómo lograr la cuadratura del círculo: cómo comerse la torta y conservarla al mismo tiempo, cómo degustar las dulces delicias de las relaciones evitando los bocados más amargos y menos tiernos [...]" (2006:9). En el caso del texto de Samanta Schweblin la relación humana descrita por Bauman se refiere a la relación madre/padrehijo/a, y, por supuesto, ese deseo contradictorio causa una carga emocional y moral que Bauman describe como un estado de confusión, incertidumbre y angustia. Destacamos tres momentos del texto de Schweblin para observar cómo se nos presenta este fenómeno mediante el lenguaje literario del cuento. Las tres citas muestran cómo la protagonista se preocupa cada vez más por las consecuencias del planeado undo del embarazo:

1. Me cuesta hacerme a la idea de recibir a Teresita tan temprano, pero tampoco quiero lastimarla.

2. La sensación es todo lo contrario a lo que se siente al emprender un viaje. [...] Es como si al mejor año de tu vida le agregaras un año más, bajo las mismas condiciones. Es la oportunidad de seguir en continuado.

3. Tengo miedo. Temo que algo pueda salir mal y lastimemos a Teresita. Quizás ella sepa lo que está pasando, quizá todo esto esté muy mal. Manuel entra a la habitación y corre hasta mí.

-Yo sólo quiero dejarlo para más adelante... -le digo-, no quiero que... (Schweblin, 2017). 


\section{Undo, redo, delete: visiones del hogar y sus implicaciones}

en la literatura hispanoamericana contemporánea

Estas citas y la última frase inconclusa ponen de relieve que, aunque con la ayuda de una solución fantástica o de ciencia ficción los personajes del cuento consiguen deshacer algo (undo) que desean, en el momento dado resulta que la solución que encontraron tiene un precio que no necesariamente están dispuestos a pagar. Volviendo a la aproximación teórica de Bauman, lo que ocurre es que "la atención humana tiende a concentrarse actualmente en la satisfacción [...]" y que "el precio de la satisfacción que producen [las relaciones humanas, el hecho de tener un hijo en este caso] suele considerarse excesivo e inaceptable" (2006:9).

\section{Una sociedad de undos y redos sistematizados - "El mismo río" de Ana María Shua}

En caso del texto de Ana María Shua podemos hablar de una ciencia ficción más propiamente dicha, ya que los personajes del cuento titulado "El mismo río" viven en el futuro donde podemos observar otro fenómeno. Esta vez el deseo de deshacer y rehacer no se mantiene dentro del marco de una decisión personal, sino que se convierte en algo que ya forma parte del funcionamiento de la sociedad. En este futuro imaginado de la narración el método de undo y redo, o la liquidez de las relaciones humanas y de los hogares está institucionalizado.

El cuento narra la historia de una familia en la futura Argentina. El punto de partida es una noche normal y corriente de padres e hijos que esperan a los abuelos a cenar. Félix y Clari, marido y mujer, preparan la cena, mientras los hijos, Lobito, Adelaida y Patricio se entretienen: los dos primeros con un aparato llamado bugui (u orgasmatrón), que sirve para ver en una pantalla los deseos cumplidos de cada uno, y el tercer hijo en su habitación, en la planta superior del piso. Éste último, el mayor es un adolescente al que, según piensa la madre, está pasando por un difícil periodo de su vida, un "pasaje a la adultez" que se manifiesta en una serie de costumbres que resultan curiosas (raras) en su contexto: ponerse los zapatos de la semana pasada, no usar un cepillo de dientes nuevo cada día, o no usar ropa descartable. Patricio, el adolescente, desaparece en momento dado, en el piso de arriba, y al cabo de un rato se oye un gran ruido, los padres suben y resulta que el chico se suicidó. En este punto de la narración nos esperan aún más sorpresas, ya que no entendemos por qué la preocupación de los padres es limpiar la sangre, avisar a una tal "asistencia" y elegir el momento adecuado para decírselo a los 
abuelos: antes o después de la cena. Más tarde nos enteramos de que en esta sociedad futura de la Argentina ya solo es la gente miserable que usa "métodos de reproducción naturales, como los animales", los demás reciben a sus hijos en el llamado "reparto" lo que significa que la gente cada cuanto obtiene una familia nueva, con hijos o sin ellos. Esto explica la reacción de Félix y Clari a la hora del suicidio de su hijo adolescente recién sorteado. Es decir, en esta visión del futuro, las familias son desintegradas y reintegradas cada cierto periodo. Se trata de una serie de undo-s y redo-s sistemáticos, dependiendo de cómo funciona uno o una en el papel que le haya tocado en la familia dada. En este mundo utópico (o distópico) la imposibilidad de mantener relaciones (afectivas, de pareja, e incluso familiares) durante toda la vida es una evidencia y nos muestra cómo es este mecanismo que se ha inventado para los futuros habitantes de la moderna sociedad líquida para superar la angustia, la inseguridad y la fragilidad que pueden causar los deseos contradictorios, resultados de la vida y amor líquidos de nuestro pasado inmediato y nuestro presente.

Bauman, en su texto sobre "el amor líquido", caracteriza el fenómeno y la problemática de la siguiente manera:

Sueltos, deben conectarse $[\ldots]$ y esa conexión no debe estar bien anudada, para que sea posible desatarla rápidamente cuando las condiciones cambien... algo que en la modernidad líquida seguramente ocurrirá una y otra vez. [...] El sentimiento de inseguridad que esa fragilidad inspira y los deseos conflictivos que ese sentimiento despierta, provocan el impulso de estrechar los lazos, pero manteniéndolos al mismo tiempo flojos para poder desanudarlos (Bauman, 2006:7).

La pregunta es, si se sistematiza o se institucionaliza el cambio de las condiciones una y otra vez, si este nuevo orden ¿puede hacer desaparecer (borrar, delete) la angustia y la inseguridad emocional y moral causadas por -lo que Bauman llama- la "vida líquida"? Destacamos dos elementos de la narración de Shua, relacionados a la institucionalización de la liquidez: un aparato que sirve para evitar frustraciones y ver cumplirse los deseos, y la aparición de los recuerdos del pasado como referencia (sobre todo para el lector), en forma de un diálogo con los abuelos donde la familia habla explícitamente de los cambios y la diferencia entre el sistema del "reparto" y cómo funcionaban las cosas en "los viejos tiempos". 
Como hemos mencionado, una de las soluciones de esta sociedad futura para evitar frustraciones y angustias es una máquina, un aparato que proyecta en una pantalla el mundo virtual de los deseos cumplidos. Mayoritariamente los deseos sexuales, pero no exclusivamente. Cuando alguien está de mal humor, se siente frustrado o no es capaz de controlar sus emociones, entra en esta máquina y se sumerge en un mundo feliz donde en el espacio virtual se realizan todos sus sueños. En caso de los hijos que usan el aparato a la manera de "indígenas digitales" o "indígenas de la virtualidad", es decir, que forma parte de su vida como el teléfono móvil de la nuestra, recurren al mundo virtual de los deseos en cada caso cuando no pueden manejar los sentimientos provocados por la realidad. Hay varios ejemplos en la historia, como cuando la niña se entera de la muerte de su hermano: "Le dijeron a Adelaida, que se impresionó mucho y, después de un rato, pidió permiso en voz baja para entrar un poquito más al orgasmatrón" (Shua, 2006). Cuando el marido-padre llega a su casa, dos de sus tres hijos están en el aparato, en el "bugui-bugui", los mira y los describe de esta manera: "Los chicos estaban en el bugui-bugui: Lobito y Adelaida. [...] Echó una mirada a las caras extasiadas, a los cuerpos estremecidos y lo que vio en las pantallas le pareció bien" (Shua, 2006).

La esposa-madre también habla del buen efecto de pasar tiempo en el mundo virtual de "los sueños realizados". Dice: "Hay que ver cómo quedan sedados, después [...] Se duermen a las nueve como dos benditos" (Shua, 2006). Más tarde nos enteramos también de qué es de lo que sueñan los hijos: "Antes de desenchufar el aparato [Félix] volvió a controlar las fantasías sexuales de los chicos que, proyectadas en las pantallas, acompañaban el infinitamente lento y maravilloso orgasmo del bugui" (Shua, 2006). Resulta que uno de los hijos, el chico, fantasea con su nueva profesora de matemáticas, mientras la hija sobre marineros en un barco. Félix está contento de los deseos de sus hijos, parece que ya tiene mucha experiencia ( $\mathrm{y}$ muchos conocimientos e informaciones) con los deseos virtuales de los hijos sorteados. En este caso se trata más bien de unas aventuras sexuales, pero el aparato sirve también para vivir relaciones románticas. Y qué es si no de lo que habla Bauman como objetivo de los habitantes de la sociedad líquida que pueden intentar establecer "relaciones de bolsillo, que se pueden sacar en caso de necesidad", pero que también "pueden volver a sepultarse en las profundidades del bolsillo cuando no son necesarias" (2006:10), o en las profundidades de ese mundo virtual que son capaces de hacer desaparecer en cualquier momento, simplemente apagando el aparato. Pero también pueden volver a esas relaciones, encendiéndolo: undo y redo otra vez. O 
como dice Bauman respecto a las aventuras, relaciones y amores virtuales: "A diferencia de las verdaderas relaciones, [...] son de fácil acceso y salida. Parecen sensatas e higiénicas, fáciles de usar y amistosas con el usuario, cuando se las compara con la cosa real, pesada, lenta, inerte y complicada" (2006:13). Para no decir imposible.

Sin embargo, los adultos del cuento, que no son indígenas, sino solo inmigrantes en esa realidad que tiene su parte virtual, todavía recuerdan cómo era la vida antes del sistema de repartos y de las orgasmatronas, o buguis. Durante la cena con los abuelos las tres generaciones hablan de los viejos tiempos:

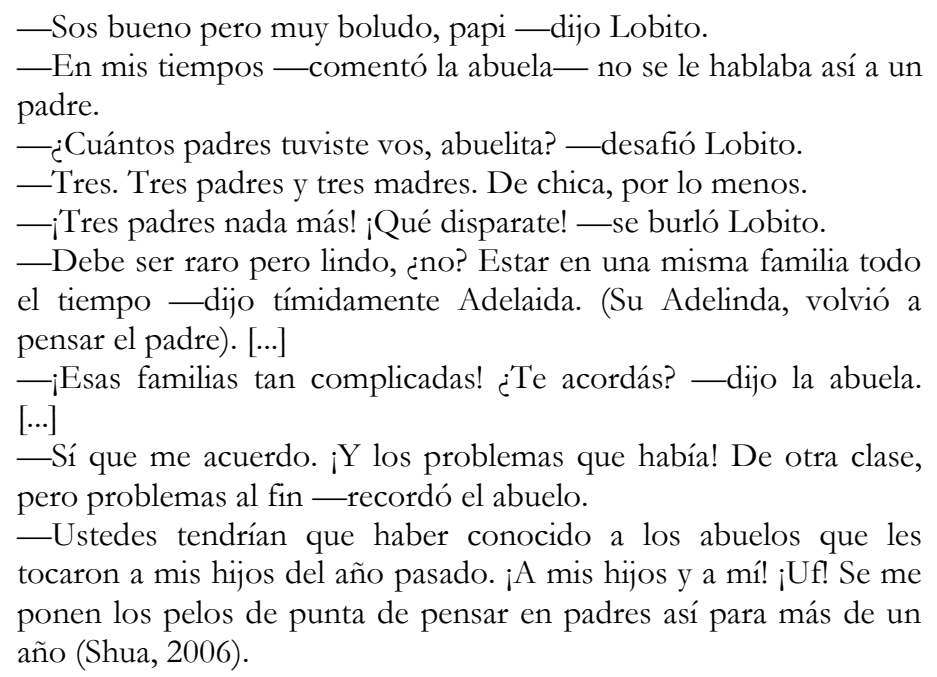

Vemos, pues, que el reparto y la liquidez estandarizada tiene sus ventajas para los protagonistas, sin embargo, también surge cierta nostalgia hacia las relaciones a la antigua, hacia "las verdaderas relaciones" con palabras de Bauman. En este futuro, o en esta otra realidad que conocemos en el cuento, los días no acaban con un abrazo de la pareja, sino, por supuesto, en el aparato de los deseos. El protagonista, Félix, que parece ser el personaje más tradicional, se acuerda con nostalgia de una mujer anterior que tenía:

Una noche (ella era su primera esposa) se había deslizado en la cama de al lado y había abrazado por detrás a la mujer ¿dormida? Ella nunca le dijo nada. Una extraña sensación que había alimentado durante mucho tiempo sus fantasías de bugui (Shua, 2006). 
El aparato, en este caso, se convierte en un medio en el que se refleja el pasado del usuario, y el deseo se convierte en un objeto autorreferencial. Pero, al mismo tiempo, ellos también se ven obligados a adaptarse a la nueva realidad que tiene la intención de solucionar los problemas de una sociedad anterior (que probablemente coincide con nuestro presente), y a pesar de la nostalgia que sienten, no hay otro remedio que aceptar los métodos y costumbres de la nueva realidad. El cuento acaba con la siguiente frase que se refiere al mismo protagonista, Félix, y alude a que no hay vuelta atrás, no hay otra opción que aceptar las condiciones y posibilidades de los tiempos "modernos líquidos": "Al final supo que también él tendría que prenderse el bugui si quería dormir esa noche" (Shua, 2006).

\section{Delete, o borrarlo todo - “Árbol genealógico” de Andrea Jeftanovic}

Con el tercer cuento, "Árbol genealógico" de la chilena Andrea Jeftanovic llegamos a una especie de delete, y a una manifestación del "narcicismo patológico" que hemos mencionado al principio.

El hogar que conocemos a través de esta historia es el de una familia donde la madre abandona la familia, y el padre se queda solo con la hija que en aquel entonces tiene nueve años, y en el momento de la narración, catorce. Después de la desaparición de su esposa, el padre busca relaciones con otras mujeres, pero la hija prácticamente se lo impide. Al principio parece que se trata de celos, el narrador que es el mismo padre lo explica así: "Era absurdo, pero me sentía acorralado, acosado por mi propia hija. Me la imaginaba como un animal en celo que no distinguía a su presa. Se arrastraba por las paredes con el pelaje erizado, el hocico húmedo, las orejas caídas" (Jeftanovic, 2009:118). Pero luego, a lo largo de la historia la niña poco a poco intenta ocupar el sitio de su madre ausente y aunque al padre al principio le parecen ridículos estos intentos de su hija: "De todos modos su ropa infantil, su cuerpo de niña, se veían algo grotescos en esa máscara de adulto", y no quiere darse cuenta de los coqueteos de ella, como cuando por ejemplo "Se subía la falda y se agachaba a tirar la basura dejando a la vista sus pequeños calzones" (2009:118), al final, cuando se van de vacaciones a una casa fuera de la ciudad, la niña consigue vencer la resistencia de su padre: "Una noche no fui capaz de esquivar su seducción. Nos hundimos en el colchón" (2009:120). 
Sin embargo, no se trata de una simple pederastia por parte del padre y de una manifestación del complejo de Electra por parte de la hija, los dos se reflejan en los ojos del otro, en la lectura del padre los dos buscan y ven a sí mismos en el otro: "Yo sobre ella mirando esos ojos grises, que eran mis ojos grises. Me estaba besando a mí mismo. Me estaba acariciando en los huesos marcados, estaba chocando contra mi propia nariz aguileña, calcando mi frente estrecha" (2009:120). Pero tampoco se trata solo de un acto narcisista, no es un asunto personal o familiar, sino un plan que a largo plazo afecta toda la sociedad y que atribuye a ellos, padre e hija, un papel fundamental. Es decir, el propósito final va mucho más allá del incesto. Un día la niña dibuja un árbol y se lo da a su padre. Él, primero, piensa que es un dibujo de niños, quizá el último de su infancia. Pero no, es un árbol genealógico:

\footnotetext{
Era un árbol frondoso, de un solo tronco, desde el cual se desprendían muchas ramas de las que, a su vez, salían más ramas. En cada rama aparecía un cuadrado, con un nombre masculino en su interior, y un círculo con un nombre femenino. Las figuras geométricas se iban multiplicando en forma exponencial en las cuatro generaciones esbozadas.

—¿Qué significa esto?

-Nuestro clan. Nosotros estamos en la base (Jeftanovic, 2009:121).
}

Lo que la niña pretende es fundar una nueva sociedad, una nueva especie donde todos son una misma familia, borrando (delete) todo tipo de otredad, donde el compromiso que según Bauman falta de la "modernidad líquida", ya está dado, está en los genes y no es un deber que requiera un esfuerzo continuo, ya que esencialmente todos van a ser un mismo yo: "Yo, mil veces nacido en mis hijos, en mis nietos, sobrinos, primos" (Jeftanovic, 2009:123).

\section{Posibles conclusiones de undo, redo y delete}

Concluyendo, hemos visto tres textos, de tres autoras latinoamericanas, en los que aparecen tres diferentes propuestas literarias sobre las consecuencias en el hogar de lo que Bauman llama "modernidad, vida y amor líquidos", donde el hecho de poder oprimir la tecla delete aparece como una ventaja decisiva de las relaciones "posibles de desatar rápidamente" y en cualquier momento, comparando con las relaciones clásicas que requieren compromiso, esfuerzo y adaptación. 


\section{Undo, redo, delete: visiones del hogar y sus implicaciones \\ en la literatura hispanoamericana contemporánea}

Nuestra propuesta ha sido observar en los tres cuentos el mecanismo de deshacer (undo), y volver a aplicar el cambio (redo) en relación a distintos aspectos de los nexos humanos dentro de contextos familiares, y de hogares. En "Conservas" hemos visto una solución personal a un problema familiar, a querer efectuar "un pequeño cambio en la organización de los hechos" (Schweblin, 2017) justamente con la ayuda de los dos procedimientos mencionados. En "El mismo río" ya encontramos toda una sociedad que funciona con una un constante "deshacer" (undo) y "volver a hacer" (redo), con la ayuda de un aparato que hace posible vivir encuentros (sexuales y románticos) virtuales, así como con la del sistema del llamado "reparto" gracias al cual cada uno puede (y tiene que) cambiar de pareja, de hijos, y de familia, con una periodicidad determinada.

Y al final, en el texto titulado "Árbol genealógico" llegamos al deseo y a la aplicación de hacer desaparecer toda otredad no solo del hogar propiamente dicho, sino del hogar en el sentido más amplio posible. Los protagonistas de este cuento se proponen fundar una nueva sociedad, una nueva especie humana, borrando, delete, todo en lo que han vivido hasta ese momento. La única pregunta que queda es en qué modo piensan efectuarlo: en el modo de insert, inserción, o sea, insertando lo nuevo en lo que ya tenemos, o en el modo de overwrighting, sobrescribiendo, es decir, borrando lo que había existido antes, del todo y para siempre.

\section{Bibliografía}

Bauman, Zygmunt. 2017. Vida líquida (trad. por Santos Mosquera, Albino). Barcelona: Paidós.

Bauman, Zygmunt. 2006. Amor líquido. Acerca de la fragilidad de los vinculos humanos (trad. por Rosenberg, Mirta y Arrambide, Jaime). Buenos Aires: Fondo de Cultura Económica.

Csányi, Vilmos. 2015. Íme, az ember. A humánetológus szemével. Budapest: Libri. Jeftanovic, Andrea. 2009. “Árbol genealógico” Trelles Paz, Diego (ed.). El futuro no es nuestro. Buenos Aires: Eterna Cadencia Editora. 113-124.

Schweblin, Samantha. 2017. Pájaros en la boca y otros cuentos. Barcelona: Literatura Random House (edición digital). 
Shua, Ana María. 2006. "El mismo río" Carletti Eduardo J. (ed.). Axxón, Ciencia ficción en Bits, 169. Fecha de consulta: 1 de marzo de 2018. Asequible en: http://axxon.com.ar/rev/169/c-169cuento17.htm

significado-diccionario.com. Fecha de consulta: 1 de marzo de 2018. Asequible en: http://www.significado-diccionario.com

Zimbardo, Philip, Coulombe, Nikita D. 2015. Man (Dis)connected. London: Rider. Žižek, Slavoj. 2014. Pedir lo imposible. Madrid: Akal. 